\title{
Kernos
}

Revue internationale et pluridisciplinaire de religion grecque antique

$10 \mid 1997$

Varia

\section{S. BYL, L. COUlOUBARITSIS (éds), Mythe et Philosophie dans les Nuées d'Aristophane}

\section{André Motte}

\section{OpenEdition}

Journals

Édition électronique

URL : http://journals.openedition.org/kernos/683

DOI : $10.4000 /$ kernos.683

ISSN : 2034-7871

\section{Éditeur}

Centre international d'étude de la religion grecque antique

\section{Édition imprimée}

Date de publication : 1 janvier 1997

Pagination : 347-348

ISSN : 0776-3824

\section{Référence électronique}

André Motte, «S. BYL, L. couloubaritsis (éds), Mythe et Philosophie dans les Nuées d'Aristophane », Kernos [En ligne], 10 | 1997, mis en ligne le 12 avril 2011, consulté le 21 septembre 2020. URL : http:// journals.openedition.org/kernos/683; DOI : https://doi.org/10.4000/kernos.683 
l'intégration du héros parmi les dieux. L'union d'Hébé et d'Héraclès ne sera pas féconde car elle vise avant tout l'abolition des tensions, l'ataraxia incompatible avec la notion de descendance, de devenir, de lendemain. - Claudine LEDUC (Atbéna et Héraklès : une parenté botanique?), au départ de la coupe de Douris représentant Athéna versant une libation à Héraclès devant un olivier, nous propose une ingénieuse explication botanique des parentés du héros et de la déesse : Athéna à l'olivier-élaia, l'arbre féminin et vierge, d'une part, Héraclès à la massue en bois d'olivier-kotinos, mâle et sauvage, affirmant sa sexualité notamment dans le port de cette arme, d'autre part. Affaire à suivre, assurément. - Colette JOURDAIN-ANNEQUIN (Héraclès et les divinités féminines), entre le mythe panhellénique, qui voit surtout Héra et Athéna autour d'Héraclès, et les cultes et mythes épichoriques, où le côtoient Aphrodite, Artémis et les Deux Déesses, montre l'importance des cités dans la structuration de leur patrimoine mythique et cultuel local.

Vinciane PIRENNE-DELFORGE

(Université de Liège)

Simon Byl, Lambros Couloubaritsis (éds), Mythe et Philosophie dans les Nuées d'Aristophane, Bruxelles, Éditions Ousia, 1994. 1 vol. $14 \times 21 \mathrm{~cm}$, 253 p. (Ébauches). ISBN : 2-87060-043-7.

Outre un avant-propos et de brèves conclusions soulignant l'extraordinaire richesse des Nuées, l'ouvrage se compose de sept communications qui ont été présentées au Centre de philosophie ancienne de l'Université Libre de Bruxelles; elles sont autant de lectures différentes de la pièce, et plusieurs s'intéressent aux éléments religieux qu'elle véhicule. Dans son article intitulé « Les Mystères d'Éleusis dans les Nuées », S. BYL rassemble, en les complétant, les données de plusieurs études publiées depuis 1980 et qui tendent à montrer que l'initiation éleusinienne forme la toile de fond d'une grande partie de cette comédie, en dépit du fait que le nom de la cité attique n'y est jamais prononcé; les scholiastes antiques et médiévaux, à la différence des philologues modernes, avaient déjà, note-t-il, remarqué le fait. La démonstration, très convaincante, s'appuie sur plusieurs dizaines d'allusions détectées par l'auteur et commentées par lui avec une fine érudition. Aucune impiété n'est décelée envers ces Mystères auxquels Aristophane, conclut-il, était sans doute initié.

L. Couloubaritsis réfléchit pour sa part sur la portée de cette parodie, estimant que la comédie va plus loin et vise à porter en dérision le savoir sophistique ainsi que la légende liée aux Mystères éleusiniens dont se fait l'écho Hérodote (VIII, 65). M. MEULDER montre que la pièce était censée se dérouler le jour même où avait lieu l'initiation éleusisinienne, le 20 Boédromion; il vise aussi à établir que la conception de l'air qu'Aristophane emprunte à Diogène d'Apollonie aurait un caractère mystique qui le met en relation avec les rites initiatiques et que le rôle attribué au chœur des Nuées à la fin de la pièce rappelle celui des Erinyes eschiléennes. P.-J. DEHON, relevant l'abondance de références aux divinités traditionnelles, reconnaît dans la pièce un plaidoyer tendant à réhabiliter la religion ancestrale.

Les contributions de Fr. RONSMANS et de B. DECHARNEUX concernent respectivement les emprunts faits à Diogène d'Apollonie et le personnage de Socrate, notamment son caractère d'initié. 
Cet ouvrage, qui enrichit de façon originale notre connaissance des Nuées, se termine par une bibliographie sélective, forte d'environ quatre-vingt titres.

André MOTTE

(Université de Liège)

Joachim Lacrosse, L'amour chez Plotin. Erôs hénologique, Erôs noétique, Erôs psychique, Bruxelles, Éditions Ousia, 1994. 1 vol. $14 \times 21 \mathrm{~cm}$, 143 p. (Cabiers de pbilosopbie ancienne). ISBN : 2-87060-044-5.

Il existait déjà, sur la figure d'Éros chez Plotin, une littérature assez abondante, mais on se réjouira de voir ici le thème exploré d'une façon systématique qui permet à la fois d'en aborder les multiples facettes et de les replacer ensuite dans une perspective globale. La première partie est opportunément consacrée à l'exégèse des données platoniciennes exploitées par le lointain disciple; continuités et ruptures y sont bien mises en évidence, ce qui constitue une excellente introduction aux différents thèmes plotiniens examinés dans la suite. Dans le second chapitre, l'érôs est étudié dans ses rapports avec la conversion de l'âme et avec celle du Nô̂s vers l'Un; l'occasion se présente ici d'aborder la démonologie de Plotin, - Érôs est identifié au « Grand Démon »-, et sa morale sexuelle. Le dernier chapitre examine un aspect moins connu du thème, bien que le plus original et le plus fondamental, celui de l'Érôs hénologique, l'amour de soi par lequel l'Un engendre, sans en être altéré, les réalités issues de lui. C'est ici que l'on perçoit notamment combien l'érôs et le logos sont très étroitement associés. Une synthèse éclairante est fournie dans la conclusion justement intitulée «L'omniprésence de l'amour ». Importante bibliographie.

André MOTTE

(Université de Liège)

Marie-Madeleine Mactoux, Evelyne GeNy (éds), Discours religieux dans l'Antiquité. Actes du colloque (Besançon, 27-28 janvier 1995), Paris, Les Belles Lettres, 1995. 1 vol. 15,5 ×24 cm, 322 p. (Annales littéraires de l'Université de Besançon, 578. Centre de Recherches d'Histoire ancienne, 150). ISBN : 2-251-60578-9.

Les 15 communications que reproduisent ces Actes couvrent une vaste période qui va d'Hésiode à Vincent de Lérins, un auteur chrétien du $v^{\mathrm{e}}$ siècle, et la thématique abordée, tant en ce qui concerne les types de discours religieux pris en compte que les analyses auxquelles on les soumet, présente à son tour une grande diversité. Aussi n'est-il pas inutile de prendre d'abord connaissance de l'avant-propos synthétique, dû à M.-M. MACTouX, avant d'entamer la lecture de l'ouvrage; y sont notamment présentées les trois pistes de réflexion qui ont servi à regrouper les interventions. La première est centrée sur les « destinataires et la réception des discours religieux inscrits dans les discours eux-mêmes sous diverses modalités ». Une contribution de Cl. CALAME (Invocations et commentaires "orpbiques": transpositions funéraires de discours religieux) ouvre cette série; riche d'érudition et d'observations minutieuses, mais d'une lecture difficile, elle confronte, dans leurs fonctions énonciative et performative, deux types de discours "mystiques " et à usage funéraire, le papyrus de Dervéni et les deux lamelles d'or récemment découvertes à Pélinna. J.-M. PAILler 